\title{
KILOMETER-SIZED WAVES IN ELECTRON DENSITY IN THE VENUSIAN NIGHTSIDE IONOSPHERE
}

\author{
Larry H. Brace
}

Space Physics Research Laboratory, The University of Michigan

\begin{abstract}
As periapsis of the Pioneer Venus Orbiter (PVO) descended into the lower nightside ionosphere of Venus in the Fall of 1992, wave-like ionospheric density structures began to appear on some of the volt-ampere characteristics of the Orbiter Electron Temperature Probe. The number of such events is insufficient to fully define their morphology but enough to provide an indication of the wave amplitudes, scale sizes, occurrence altitudes, and local time variation. The density variations were quasi-sinudoidal, with wavelengths of the order of $1 \mathrm{~km}$ along the nearly horizontal trajectory near periapsis. Nearly all of the wave events were encountered within an altitude band lying between 140 and $160 \mathrm{~km}$, a region containing the steep negative $\mathrm{N}_{\mathrm{e}}$ gradient just above the ionospheric peak. The waves generally did not fill the occurrence band but were seen primarily as isolated events on curves taken intermittently as PVO crossed through the band. Peak-to-trough amplitudes $(\Delta N / N)$ were in the range of $5 \%$ to $50 \%$. The waves exhibited little local time variation within the available viewing period (01-04 hrs), with perhaps a tendency for the waves to rise to slightly higher altitudes toward dawn. The latitudinal extent of the waves could not be resolved because volt-ampere curves were obtained only intermittent, however, their occurrence on both inbound and outbound passages through the wave band suggests that the waves sometimes exist in layers that extend over at least $15^{\circ}$ of latitude. The generation mechanism for these waves is unknown, but we suspect that it involves the steep density gradient that separates the main nightside ionosphere from the tenuous, and probably rapidly flowing plasma above.
\end{abstract}

\section{Introduction}

During the final month or so of its lifetime, the Pioneer Venus Orbiter (PVO) used its remaining fuel to make a unique series of very low altitude excursions into the nightside ionosphere of Venus. The resulting in situ measurements were especially valuable for two reasons. First, the measurements extended to much lower altitudes than were achieved during the low altitude operations in 1979 and 1980 when PVO last operated deep in the ionosphere. Second, the level of solar activity was much lower during the entry period (F10.7 cm index $\approx 120)$ than during the $1979-80$ period $(\approx 220)$ when such low altitude measurements were last possible. The examination of data from these two periods has allowed the ionospheric response to solar activity to be assessed (Theis and Brace, 1993). The present work takes advantage of the lower periapsis altitudes during the entry period to investigate the characteristics and morphology of kilometer-sized waves in

Copyright 1993 by the American Geophysical Union.

Paper number 93GL02240

0094-8534/93/93GL-02240\$03.00 electron and ion density $\left(\mathrm{N}_{\mathrm{e}}\right.$ and $\mathrm{N}_{\mathrm{i}}$ ) in the nightside ionosphere. These waves appear in the Orbiter Electron Temperature Probe (OETP) measurements. An initial investigation of these waves was presented by Brace (1993). Note that Grebowsky et al. (1991) employed OETP voltampere curves taken earlier in the mission to study nightside density irregularities which are generally less wave-like and extend to much higher altitudes.

\section{The Method}

The method employed two independent Langmuir probes (radial and axial) whose potentials were swept repeatedly at a rate of $2 / \mathrm{s}$ to generate volt-ampere characteristics. Details of the method are discussed by Krehbiel, et al. (1980), and the measurements have been used extensively to investigate the Venus ionosphere (eg. Theis et al., 1984, Brace et al., 1980). Telemetry rate limitations permitted curves to be retrieved at intervals of only $16 \mathrm{~s}$ or $32 \mathrm{~s}$, which corresponded to distances along the orbit of $160 \mathrm{~km}$ and $320 \mathrm{~km}$, respectively. However, each retrieved curve was sampled at $10 \mathrm{~ms}$ intervals, thus providing a spatial resolution of about $100 \mathrm{~m}$ along the trajectory. These curves are of particular interest here because they provided the $500 \mathrm{~ms}$ snapshots of wave trains which are the topic of this study.

To illustrate the method and some of the wave signatures, Figure 1 shows individual radial probe curves taken near periapsis during 4 different orbits during the PVO entry period. The curve at the top exhibited no density structure and is typical of the vast majority of curves taken in the Venus ionosphere, while the others are examples of the kilometersized waves. Wavelengths of the order of $1 \mathrm{~km}$ and peak-topeak amplitudes of $30 \%$ to $50 \%$ are evident.

The volt-ampere curves are generated by sweeping the probe potential from negative to positive, so the ion saturation region is at the left and the electron saturation region is at the right. The ion current is proportional to $\mathrm{Ni}$ and the electron current is proportional to $\mathrm{Ne}_{\mathrm{e}}$. (We assume $\mathrm{Ne}_{\mathrm{e}}=\mathrm{N}_{\mathrm{i}}$ everywhere, but the technique measures them independently so either can be used to detect the waves). The electron temperature, $\mathrm{T}_{\mathrm{e}}$, is derived on the ground by fitting the exponential portion of the curve. The sharp drop in current near the end of each curve is caused by an electrometer downrange that keeps the electron current on scale. The current and voltage scales are linear, and each curve was taken in $500 \mathrm{~ms}$, corresponding to a distance of $4 \mathrm{~km}$ along the orbit. The points represent the current measurements taken at $10 \mathrm{~ms}$ intervals, while the solid lines are smooth, hand-drawn through the wave structure to show what the curves might have looked like if the waves had not been present. Note that these waves reflect spatial structure in the plasma density, not electromagnetic or electrostatic plasma waves.

The spatial resolution available in the volt-ampere curves is 


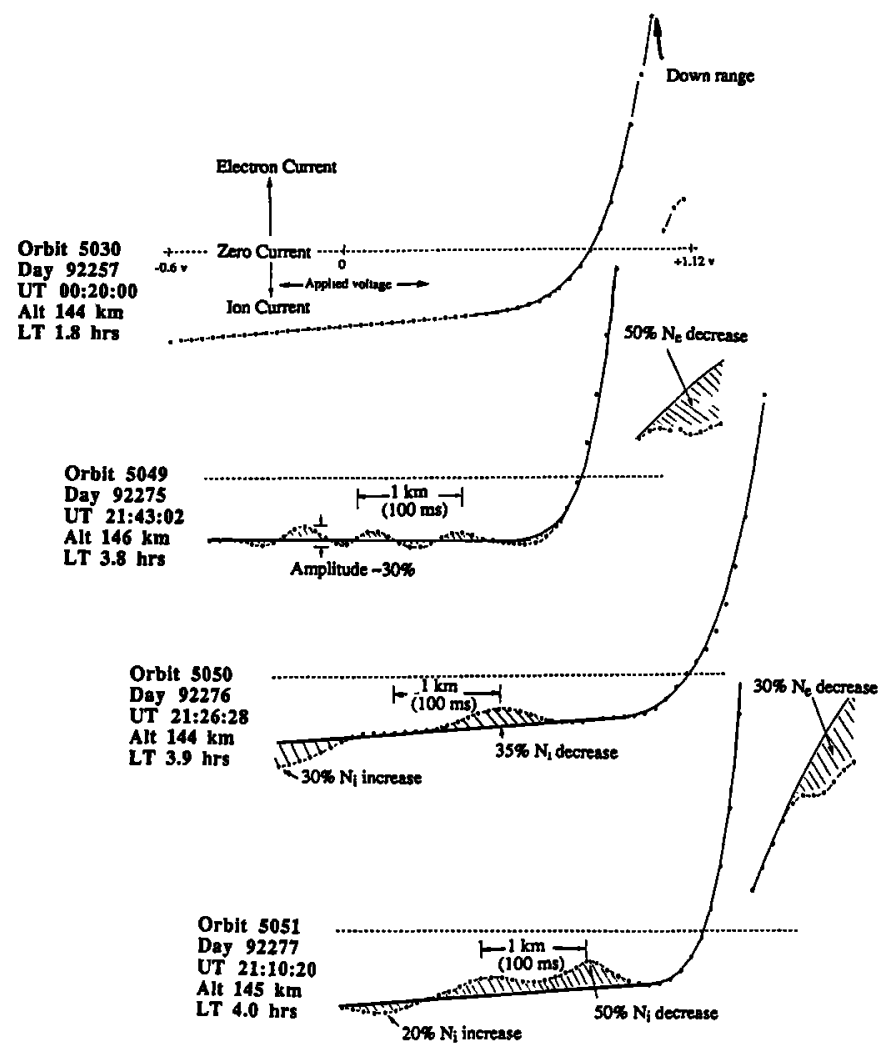

Figure 1. OETP individual volt-ampere curves from 4 different periapsis passages. Each curve is taken in $500 \mathrm{~ms}$ and sampled (solid points) at $10 \mathrm{~ms}$ intervals, thus providing $100 \mathrm{~m}$ spatial resolution along the trajectory. The top curve shows no structure and is typical of the Venus ionosphere, while the other 3 curves are examples of the kilometer-sized waves discussed here. The solid line is a smooth hand-drawn fit that is intended to show what the curve might have looked like without the waves. The waves can often be seen in both the ion current (proportional to $\mathrm{N}_{\mathrm{i}}$ ) or the electron current (proportional to $\mathrm{N}_{\mathrm{e}}$ ).

determined by the spacecraft speed, the voltage sweep rate and the telemetry sampling rate. Since the vehicle velocity at periapsis was about $10 \mathrm{~km} / \mathrm{s}$, the $10 \mathrm{~ms}$ sampling rate provided a $100 \mathrm{~m}$ spatial resolution of the wave structures. This permits the detection of irregularities having scale sizes in the range of approximately $100 \mathrm{~m}$ to $3 \mathrm{~km}$.

The precision of the current measurements determines the minimum wave amplitude that can be measured. The accuracy is believed to be adequate to detect wave amplitudes $(\Delta \mathrm{N} / \mathrm{N})>$ $1 \%$ when the density itself exceeded $10^{3} \mathrm{~cm}^{-3}$, as it did in all cases included in this study. To avoid confusion with smaller amplitude and less regular density structures which may occur anywhere in the ionosphere (Grebowsky, et al., 1991), this study included only quasi-periodic waves with amplitudes exceeding about $5 \%$.

\section{Morphology of the Waves}

During the final 36 days of the PVO mission, propulsion was employed to lift periapsis by about $15 \mathrm{~km}$ each time it fell below approximately $135 \mathrm{~km}$ where it was feared that

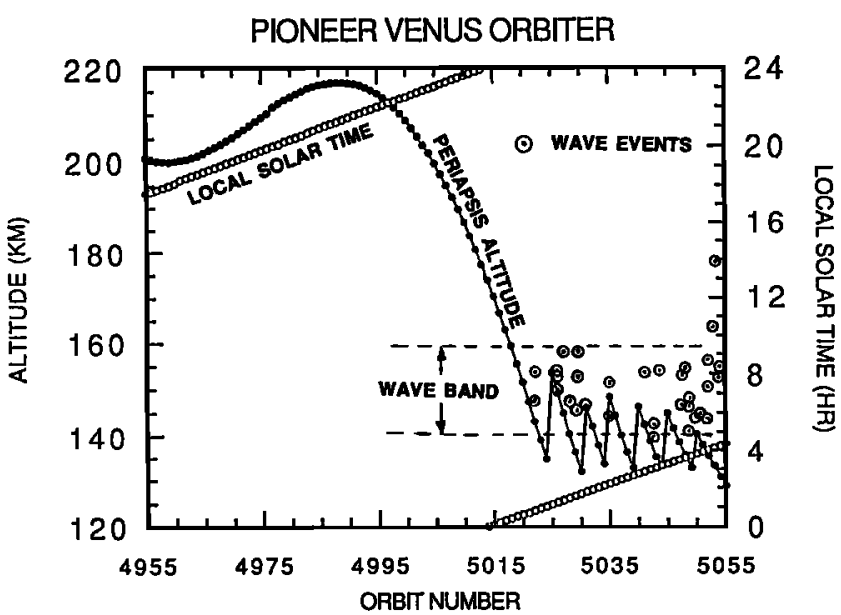

Figure 2. The altitudes of the wave events are shown superposed on a plot of periapsis altitude and local time. The waves occurred almost exclusively in a band between 140 and $160 \mathrm{~km}$, with perhaps a tendency to rise out of this band toward dawn.

aerodynamic heating could damage the spacecraft and instruments. These altitude changes can be seen in Figure 2 which shows the changing altitude and local time of periapsis during the final 100 PVO orbits prior to entry. The waves began to appear on orbit 5021 after periapsis had fallen below $150 \mathrm{~km}$. A total of 32 wave events were observed between that time and orbit 5055; the last data that were recovered. The altitude of these events are also shown in Figure 2. The local time of periapsis drifted from 0100 to $0400 \mathrm{hrs}$ during this interval (orbits 5021-5055). It is clear that nearly all of the

Table 1. Times and Altitudes of $\mathrm{Km}$-sized Waves

\begin{tabular}{|c|c|c|c|c|}
\hline Orbit & $\begin{array}{l}\text { Date } \\
\text { (yr-day) }\end{array}$ & $\begin{array}{l}\text { UT } \\
\text { (hr:mi:sec) }\end{array}$ & $\begin{array}{l}\text { Altitude of Waves } \\
(\mathrm{km})\end{array}$ & $\begin{array}{l}\text { Periap Alt } \\
(\mathrm{km})\end{array}$ \\
\hline $\begin{array}{c}5054 \\
" \\
"\end{array}$ & $\begin{array}{l}92280 \\
92279\end{array}$ & $\begin{array}{l}20: 10: 29 \\
20: 11: 01 \\
20: 13: 41\end{array}$ & $\begin{array}{l}177 \text { inbound } \\
154 \text { inbound } \\
152 \text { outbound }\end{array}$ & 130.8 \\
\hline $\begin{array}{l}5053 \\
5052 \\
n \\
n\end{array}$ & $\begin{array}{l}92279 \\
92278\end{array}$ & $\begin{array}{l}20: 35: 25 \\
20: 51: 23 \\
20: 51: 37 \\
20: 51: 56\end{array}$ & $\begin{array}{l}162 \text { outbound } \\
156 \text { inbound } \\
149 \text { inbound } \\
142 \text { inbound }\end{array}$ & $\begin{array}{l}133.3 \\
135.6\end{array}$ \\
\hline $\begin{array}{l}5051 \\
5050 \\
5049 \\
" \\
n\end{array}$ & $\begin{array}{l}92277 \\
92276 \\
92275\end{array}$ & $\begin{array}{l}21: 10: 20 \\
21: 26: 28 \\
21: 40: 54 \\
21: 41: 10 \\
21: 43: 02\end{array}$ & $\begin{array}{l}145 \text { outbound } \\
144 \text { outbound } \\
148 \text { inbound } \\
141 \text { inbound } \\
146 \text { outbound }\end{array}$ & $\begin{array}{l}138.0 \\
140.7 \\
132.9\end{array}$ \\
\hline $\begin{array}{l}5048 \\
5047 \\
n\end{array}$ & $\begin{array}{l}92274 \\
92273\end{array}$ & $\begin{array}{l}21: 57: 12 \\
22: 07: 47 \\
22: 08: 03\end{array}$ & $\begin{array}{l}154 \text { outbound } \\
153 \text { inbound } \\
147 \text { inbound }\end{array}$ & $\begin{array}{l}135.8 \\
138.7\end{array}$ \\
\hline $\begin{array}{l}5043 \\
5042 \\
"\end{array}$ & $\begin{array}{l}92269 \\
92268\end{array}$ & $\begin{array}{l}22: 55: 14 \\
23: 05: 01 \\
23: 05: 18\end{array}$ & $\begin{array}{l}154 \text { inbound } \\
142 \text { inbound } \\
139 \text { inbound }\end{array}$ & $\begin{array}{l}135.4 \\
138.9\end{array}$ \\
\hline $\begin{array}{l}5041 \\
5035\end{array}$ & $\begin{array}{l}92267 \\
92261\end{array}$ & $\begin{array}{l}23: 13: 23 \\
23: 56: 09 \\
23: 56: 46\end{array}$ & $\begin{array}{l}154 \text { inbound } \\
144 \text { inbound } \\
151 \text { outbound }\end{array}$ & $\begin{array}{l}142.6 \\
148.5\end{array}$ \\
\hline $\begin{array}{c}5031 \\
5030 \\
" \\
"\end{array}$ & $\begin{array}{l}92258 \\
92257\end{array}$ & $\begin{array}{l}00: 15: 37 \\
00: 17: 52 \\
00: 20: 16 \\
00: 20: 32\end{array}$ & $\begin{array}{l}146 \text { outbound } \\
157 \text { inbound } \\
144 \text { outbound } \\
152 \text { outbound }\end{array}$ & $\begin{array}{l}146.7 \\
132.1\end{array}$ \\
\hline $\begin{array}{l}5029 \\
5028 \\
5026 \\
" \\
n\end{array}$ & $\begin{array}{l}92256 \\
92255 \\
92253\end{array}$ & $\begin{array}{l}00: 21: 48 \\
00: 20: 57 \\
00: 22: 45 \\
00: 23: 19 \\
00: 23: 49\end{array}$ & $\begin{array}{l}147 \text { outbound } \\
158 \text { inbound } \\
153 \text { inbound } \\
149 \text { outbound } \\
152 \text { outbound }\end{array}$ & $\begin{array}{l}136.3 \\
140.6 \\
149.3\end{array}$ \\
\hline 5021 & 92248 & $\begin{array}{l}00: 24: 18 \\
00: 24: 53\end{array}$ & $\begin{array}{l}153 \text { inbound } \\
147 \text { outbound }\end{array}$ & 147.5 \\
\hline
\end{tabular}


waves occurred in a band between 140 and $160 \mathrm{~km}$, perhaps with a tendency to rise slightly near dawn. We will call this altitude range the wave band. The earlier orbits in Figure 2 traversed the dawn-to-midnight sector at slightly higher altitudes, but no wave-like signatures were observed. To facilitate later comparisons with other types of PVO measurements, Table 1 lists the universal times, altitudes of these 32 wave events.

A common feature of the waves is that they occur just above the ionospheric peak. This is illustrated in Figure 3, which shows $\mathrm{N}_{\mathrm{e}}$ profiles from the 3 orbits which yielded the waves shown in Figure 1. The arrows indicate where the
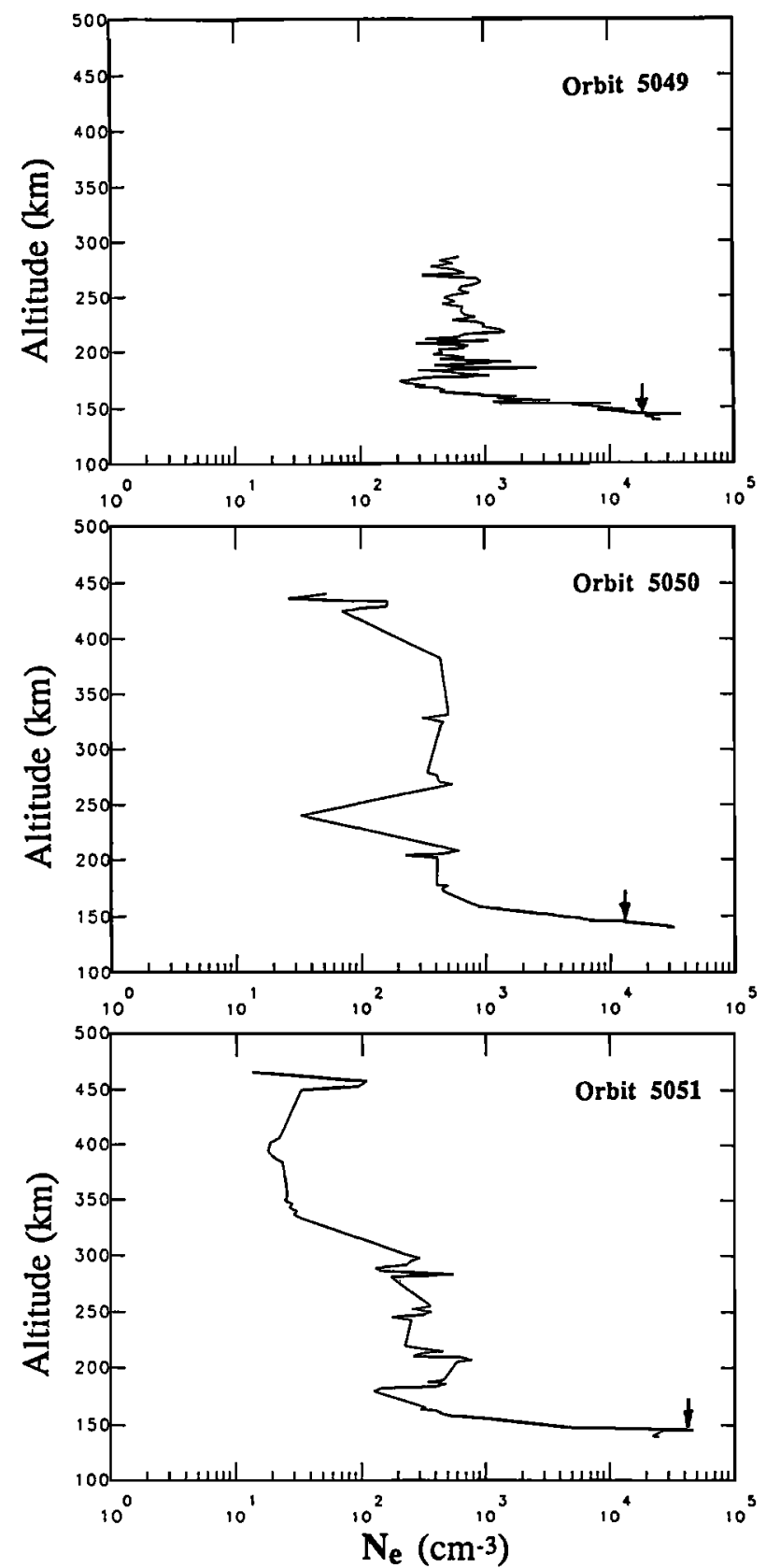

Figure 3. $\mathrm{N}_{\mathrm{e}}$ height profiles for orbits 5049, 5050, and 5051 showing that the waves occur near the high density end of the gradient above the ionospheric peak. The arrows indicate where the wave events of Figure 1 were recorded. waves were observed. They all occurred at the high density end (low altitude end) of the $\mathrm{N}_{e}$ gradient. Note in these profiles that the overlying nightside ionosphere at the time of entry also contained much larger scale structure, but we have not attempted to correlate wave occurrence with the existence of this large scale structure.

\section{Discussion}

It is interesting that the detection of such small-scale ionospheric features was entirely serendipitous. Their measurement was possible only because occasional snapshots were being taken of individual curves in order not to rely totally on the onboard curve processing circuitry that was included in the OETP electronics to derive $\mathrm{N}_{e}$ and $\mathrm{T}_{\mathrm{e}}$ from volt-ampere curves that could not be recovered owing to low data rates (Krehbiel, et al., 1980). Apparently no other PVO instrument has sufficient spatial resolution to resolve these density waves, although the plasma wave instrument (OEFD) may be able to detect associated electric fields if their harmonics extend into its $100 \mathrm{~Hz}$ channel (Scarf et al., 1980). An initial comparison of these two data sets does not show a promising correlation between density wave events and plasma wave activity (Brace, 1993). This does not preclude the existence of such a correlation, however. The density waves can only be detected intermittently, while the plasma wave activity is measured continuously.

The large spacing between volt-ampere curves will make it difficult to fully determine the morphology of the waves, however these 32 wave events provide useful insights. Several important characteristics of the waves are evident in Figures 1 and 2. The wave lengths were of the order of 1 kilometer and their amplitudes range from 5 to $50 \%$. The wave events all occurred in the nightside ionosphere at local times between 0100 and $0400 \mathrm{hrs}$, and primarily within a narrow altitude band between 140 and $160 \mathrm{~km}$. Since periapsis did not reach these altitudes until after midnight, the full local time extent of the waves cannot be determined, but we see no reason to expect them to only on the dawn side of midnight. The dusk side was sampled only at altitudes above $160 \mathrm{~km}$, and no waves were observed.

A more complete determination of the wave morphology is hampered by the fact that the encounter probability is a function of the periapsis altitude. When periapsis was at the bottom of the wave band $(\sim 140 \mathrm{~km})$ the probability of wave encounters was increased because PVO spent more time in the band during such passages. Conversely, wave encounters were less likely when periapsis occurred higher in the band. And when periapsis was well below the wave band, the spacecraft traversed the band more quickly, thus providing a smaller probability of detection. In the latter situation, only one or two waves might be detected within the entire band even if they had actually filled it.

Closer examination of the data surrounding the wave events of Figure 2 suggests that the waves do not fill the entire wave band. If they did, one would expect to see them on 2 or 3 consecutive curves taken during a single transit of the band, but these are the exception. Many of the orbits found no waves, but this does not exclude their presence in small packets or narrow altitude slices that could easily have been missed by the 16 or 32 second gaps between curves. These results imply that waves either occur sporadically within the 
wave band, or that they exist over limited horizontal distances within the band. In either case, the intermittent sampling would miss the vast majority of the waves.

A few orbits which had exceptionally low periapsis altitudes encountered waves on both inbound and outbound legs of the passage $(5030,5049,5054)$ with none observed at periapsis itself. This suggests that the waves are sometimes arrayed in horizontal layers which extend over large distances (10 to 15 degrees of latitude). But most often the waves were seen as individual events on either inbound or outbound legs (5028, 5029, 5031, 5041, 5042, 5043, 5047, 5448, 5050, $5051,5052,5053)$. Finally, there is a tendency for the waves to occur at slightly higher altitudes toward dawn.

The $\mathrm{km}$-sized density waves must be ubiquitous within the $140-160 \mathrm{~km}$ wave band. In spite of the factors that should have made them difficult to detect (rapid transit of the wave band and wide separation between volt-ampere curves), waves were observed either inbound or outbound in more than $50 \%$ of the orbits. This is a high enough detection rate that the waves must be considered a very common feature of the nightside ionosphere, at least at the low levels of solar activity that existed in September and October of 1992. Although similar wave-like features were observed on a few occasions at solar maximum (Grebowsky, et al., 1991), periapsis was not being maintained low enough to determine whether the wave morphology is the same at that time in the solar cycle. Those authors found more irregular density structures as well, and concluded that these tended to occur in regions of strong gradients in $\mathrm{Ne}$ and B. Huba and Grebowsky (1993) interpreted these higher altitude irregularities as a manifestation of the lower-hybrid-drift instability.

The mechanism for producing the kilometer-sized waves reported here is unclear. The waves clearly are associated with the steep density gradient above the ionosphere peak. They are absent above the gradient, at the peak, and below the peak $(<140 \mathrm{~km})$. Acting upon an earlier presentation of this phenomenon (Brace, 1993), Huba (1993) concluded that these waves could be produced via a collisional drift instability driven by the ExB drift of ionospheric electrons within the density gradient. The main requirement of the theory is the existence of a steep density gradient; which is consistently observed (Theis and Brace, 1993).

The question is "what causes the steep gradient?" Since ion flow from the dayside is largely cutoff at this time in the solar cycle, the strong ionospheric peak must be being maintained by impact ionization (Theis and Brace, 1993). The generation of the steep $\mathrm{N}_{\mathrm{e}}$ gradient above the peak may require a combination of a strong horizontal magnetic field to limit upward ion diffusion and an ion sink to remove ionospheric plasma from the region above. Grebowsky, et al. (1993) have presented evidence for high speed ion flows in the upper ionosphere during the PVO entry period. These flows may be a signature of upper ionosphere depletion by solar wind interactions that are as yet not fully understood. It seems likely that the kilometer-sized waves are a product of the interaction of the tenuous, rapidly flowing upper ionosphere with a denser, more quiescent main peak ionosphere.

Acknowledgements We thank the Pioneer Project at NASA/Ames Research Center for their extraordinary efforts during the Entry Period that made these unique measurements possible. This work has been funded under NASA Grant GNAG 2-644.

\section{References}

Brace, L. H., R. F. Theis, W. R. Hoegy, J. H. Wolfe, C. T. Russell, R. C. Elphic, A. F. Nagy, The Dynamic Behavior of the Venus Ionosphere, J. Geophys. Res., 85, 7663, 1980.

Brace, L. H., The Venus Ionosphere During the Pioneer Venus Orbiter Entry Period, Paper P-llA-1, Spring AGU Meeting, EOS, 74, No. 16, 186, April 20, 1993.

Grebowsky, J. M., S.A. Curtis, and L. H. Brace, SmallScale Plasma Irregularities in the Nightside Venus Ionosphere, J. Geophys. Res., 96, 21347, 1991.

Grebowsky, J. M., R. E. Hartle, J. Kar, P. A. Cloutier, and L. H. Brace, Ion Measurements in the Nightside Ionosphere of Venus Under Near Solar Minimum Conditions, Geophys. Res. Lett., this issue, 1993.

Huba, J. D., and J. M. Grebowsky, Small-scale density irregularities in the nightside Venus ionosphere: Comparison of theory and observations, J. Geophys. Res., 98, 3079, 1993.

Huba, Joseph, Theory of kilometer sized density waves in the nightside Venus ionosphere, Geophys. Res. Lett., this issue, 1993.

Krehbiel, J. P., L. H. Brace, J. R. Cutler, W. H. Pinkus, R. B. Kaplan, Pioneer Venus Orbiter Electron Temperature Probe, IEEE Transactions on Geoscience and Remote Sensing, GE-18, 49, 1980.

Scarf, F. L., W W. L. Taylor and P. F. Virobik, The Pioneer Venus Orbiter Plasma Wave Investigation, IEEE Transactions on Geoscience and Remote Sensing, GE-18, 36, 1980.

Theis, R. F., L. H. Brace, and H. G. Mayr, Empirical Models of the Electron Temperature of the Venus Ionosphere, J. Geophys. Res., 85, 7787, 1980.

Theis, R. F. and L. H. Brace, Solar Cycle Variations of the Electron Density and Temperature in the Nightside Venusian Ionosphere, Geophys. Res. Lett., this issue, 1993.

Larry H. Brace, University of Michigan

2455 Hayward, Ann Arbor, MI 48109

(Received: June 28, 1993; accepted: July 23, 1993) 